\title{
Investigation of Passive Filter Performance on Three Phase DC to AC Converter
}

\author{
Mohammad Noor, N.Rosmizi, N.Aminudin, Faranadia A.H \\ Universiti Teknologi Mara, 40450 Shah Alam, Selangor, Malaysia
}

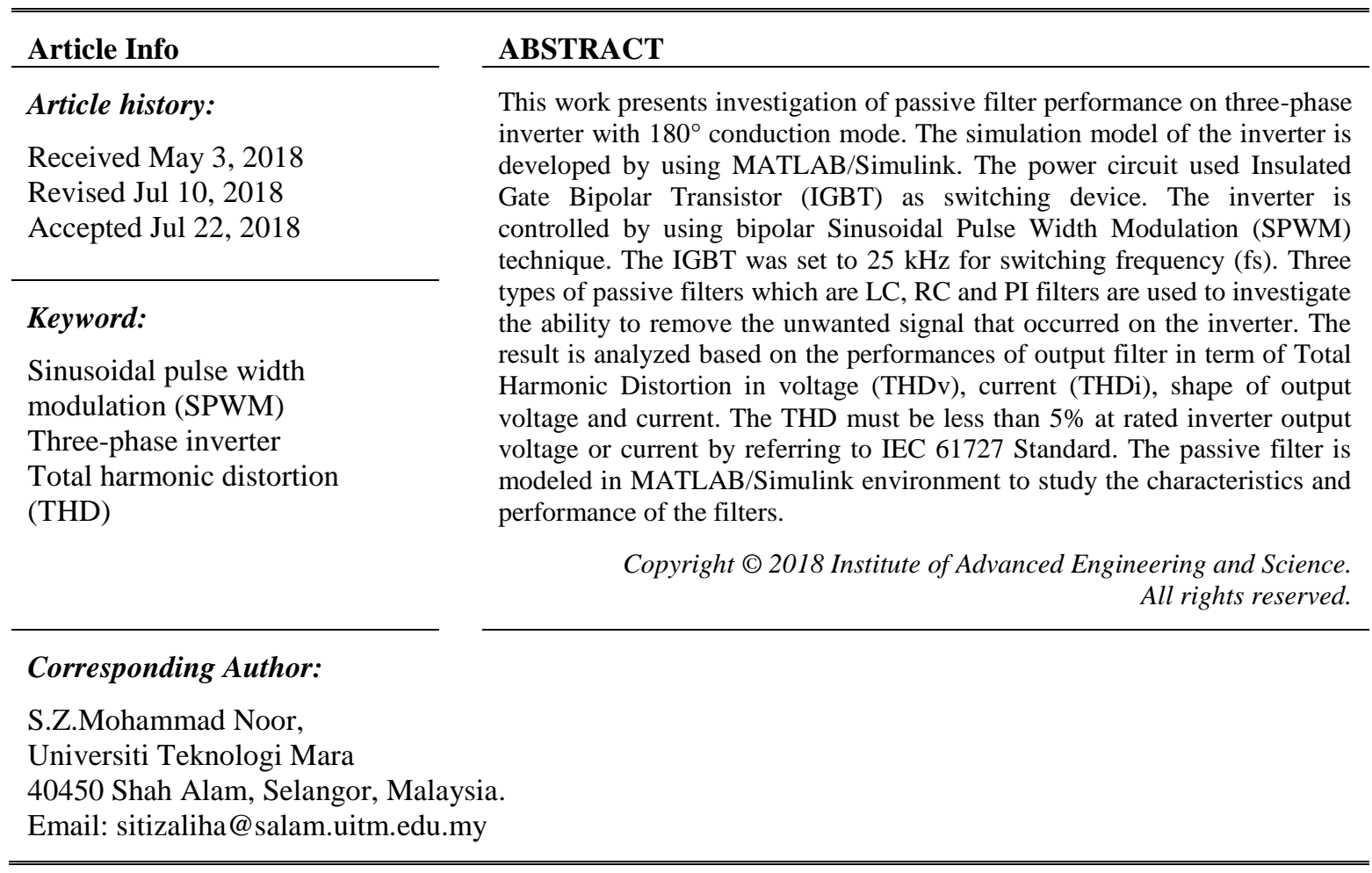

\section{INTRODUCTION}

The purpose of an inverter is to convert DC input voltage to asymmetric AC output voltage of the correct magnitude and frequency [1]. Alternating current (AC) contain distortion such as noise and unwanted signal. Harmonic current or voltage are the parameters to measure the dimensions of such interferences. The converter generates harmonics at AC side while for the DC side, the ripple will be generated which can make an unsuitable magnitude for the source or for the load [2-4]. To reduce the harmonics or ripple to an acceptable and suitable level, filters consisting mainly of inductors and capacitors are used. For power electronic converters, there is a demand for high efficiency and therefore filters must also be highly effective.

This paper discuss the development of the passive filters on three-phase inverter $180^{\circ}$ conduction mode bipolar SPWM by using MATLAB/Simulink. IGBT's are used as the power switching device for the three-phase inverter. SPWM is utilized to the synthesized output voltage and a bipolar method isy used as the switching control technique of the inverter. The switching frequency $\left(\mathrm{f}_{\mathrm{s}}\right)$ of the inverter is $25 \mathrm{kHz}$. There are three types of passive filter used in the design which is LC, RC, and PI (capacitor-input) filter. The passive filters are designed to ensure and secure the power system by limiting the harmonic current to enter the power system by providing a minimal impedance path [5]. The recommended design of the passive filter is to identify the value of Total Harmonic Distortion (THD) focused on output voltage or current of the inverter. The THD result must be less than 5\% at rated inverter output voltage or current to get the efficient inverter performance by referring to IEC 61727 Standard [6]. 


\section{HARMONIC FILTER}

The harmonic filter consists the combination of series and parallel resistance, inductance and also capacitive to reject the harmonics distortion. Passive, active and hybrid harmonic filters are the basic variety of harmonic filters. However, the most common filter that being used today are the passive and active filter. Each of the filters has their own characteristics and specifications. The function of passive filter is to modify or reject the unwanted signal that occurs in the system which can disturb the operation of electrical device output. In the proposed inverter circuit, the harmonic filter is passive type and its advantages over the active filter is illustrated in Table 1.

Table 1. The Advantage of Passive Filters over Active Filters

\begin{tabular}{ll}
\hline \multicolumn{1}{c}{ Passive Filters } & \multicolumn{1}{c}{ Active Filters } \\
\hline Less costly as it made only from passive elements & $\begin{array}{l}\text { Expensive as it made of the analog electronic filter, distinguished by } \\
\text { the use of one or more active components }\end{array}$ \\
\begin{tabular}{ll} 
Can be used for small loads as well & Can be used for large loads \\
No power consumption & Do consume energy to operate \\
\hline
\end{tabular} \\
\hline
\end{tabular}

The investigation of three-phase inverter output behavior with LC, RC and PI (capacitor-input) filter is implemented to enhance the performance of three-phase inverter and minimize the possible losses and distortion caused by switching losses and harmonic in order to achieve better power quality.

\subsection{LC filter}

LC filter is the arrangement of the inductor, $\mathrm{L}$, and a capacitor, $\mathrm{C}$ in the electric circuit. This type of filter also known as the resonant circuit or tuned circuit. The connection of this element with the load is in series for the inductor, $\mathrm{L}$ while capacitor, $\mathrm{C}$ is in shunt condition as shown in Figure 3. The LC filter circuit is very useful in signal processing and communication system. LC filtration system is a great model because it assumes there is absolutely no dissipation of energy due to resistance.

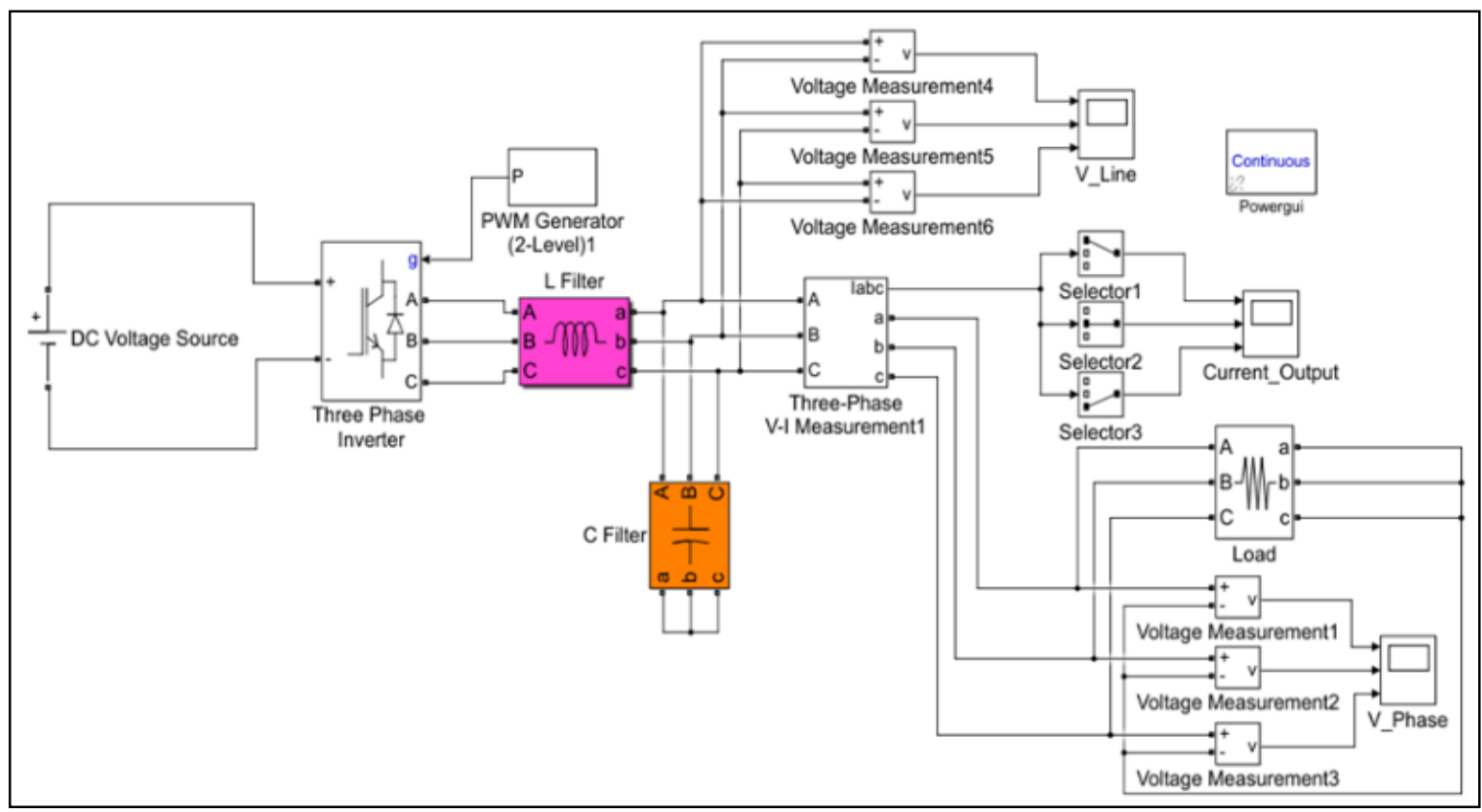

Figure 3. Three-phase inverter $180^{\circ}$ conduction mode with LC filter

\subsection{RC filter}

$\mathrm{RC}$ filter is the electric circuit that contains resistor, $\mathrm{R}$ and a capacitor, $\mathrm{C}$ driven by a voltage or current source. The straightforward $\mathrm{RC}$ circuit is a resistor, $\mathrm{R}$ and a capacitor, $\mathrm{C}$ are connected in parallel as presented in Figure 4. The capacitor will discharge its stored energy through the resistor when the circuit only contains a charged capacitor and a resistor. 


\subsection{PI filter}

The PI filter is a combination of a shunt capacitor at the input side, and it is followed by an Lsection. The design arrangement of all the components similar to the shape of Greek letter PI $(\pi)$ as shown in Figure 5. Thus, it is called PI filter. Besides, it is also defined as a capacitor-input filter when the connection of the capacitor is at the input side.

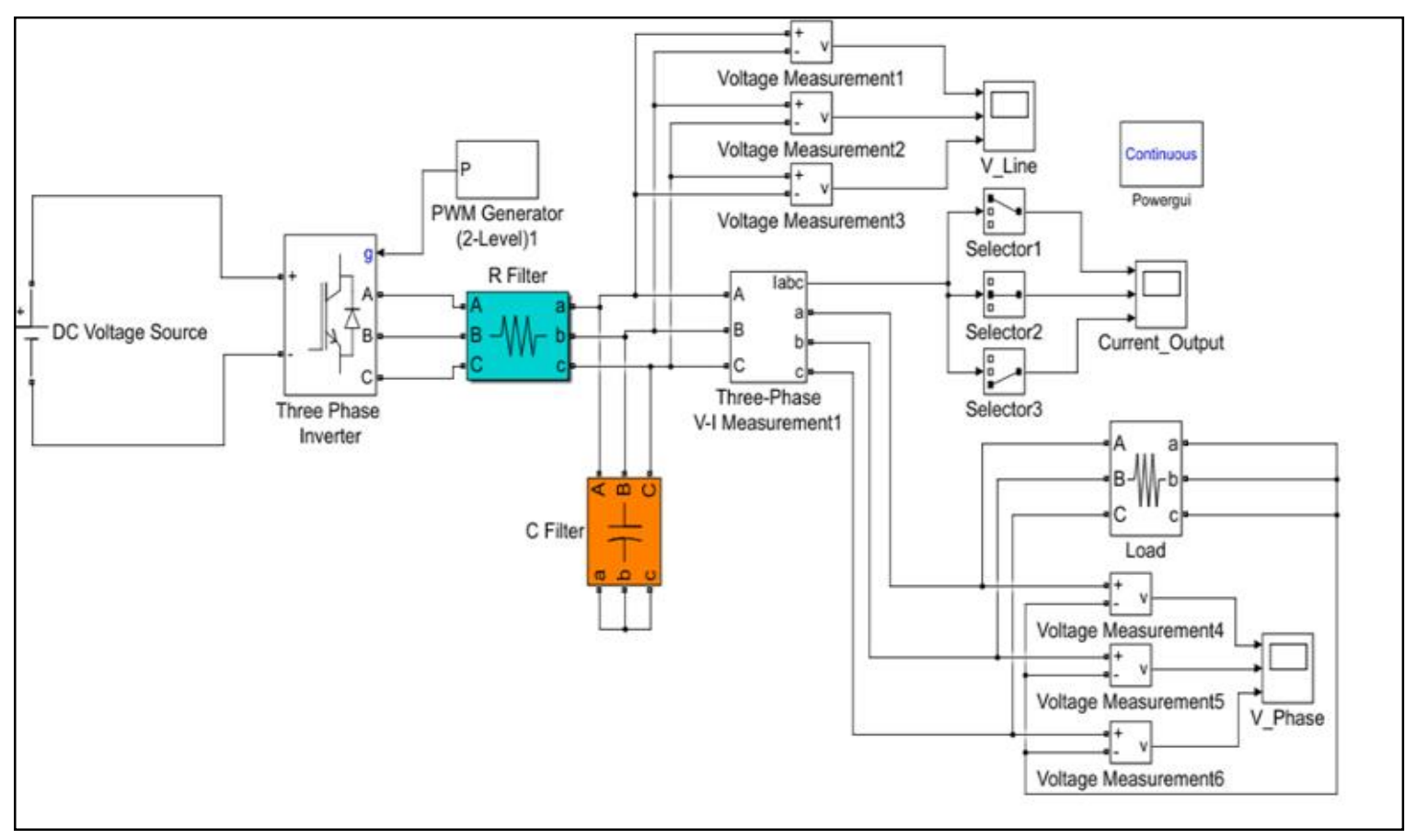

Figure 4. Three-phase inverter $180^{\circ}$ conduction mode with $\mathrm{RC}$ filter

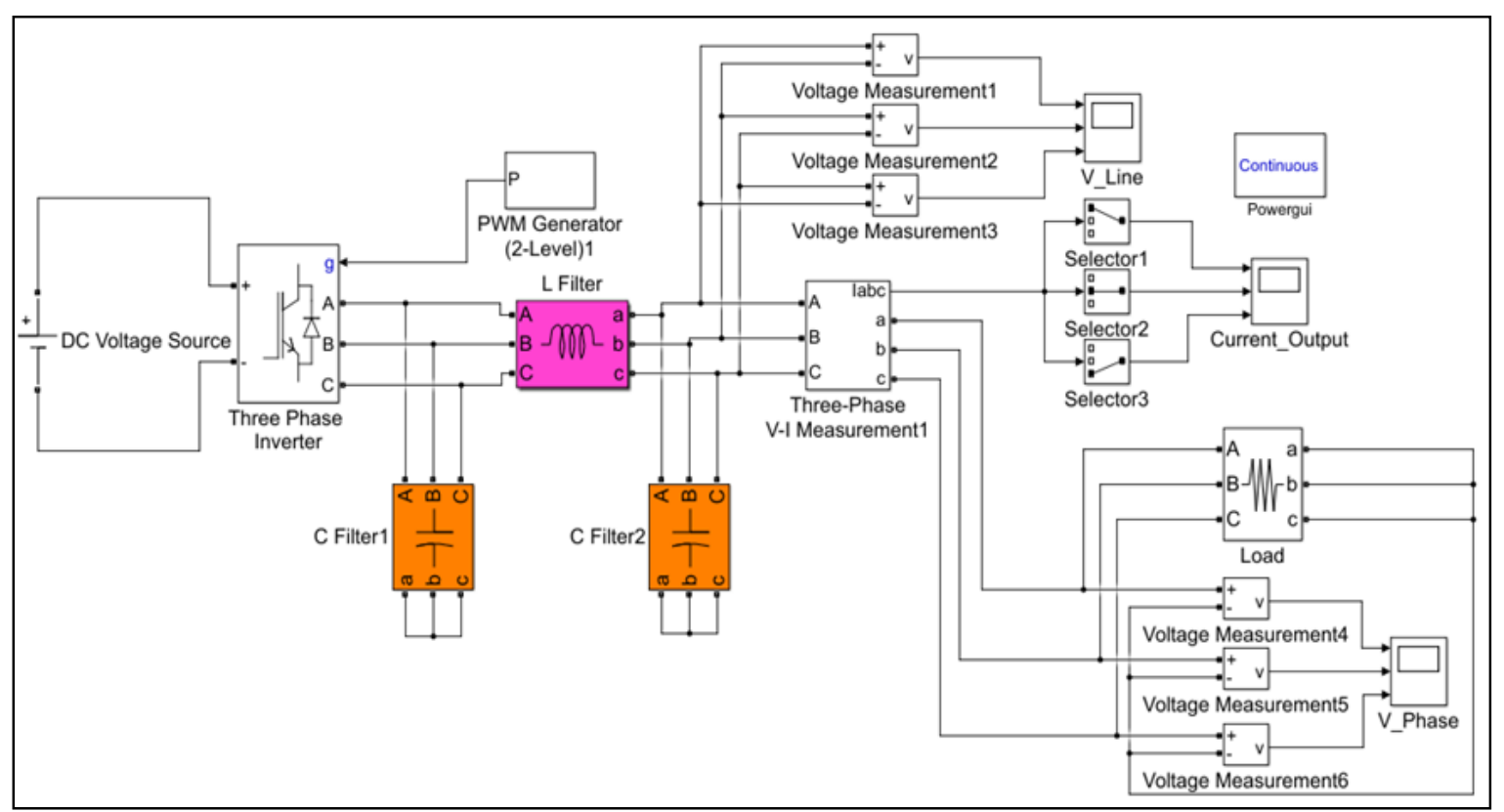

Figure 5. Three-phase inverter $180^{\circ}$ conduction mode with PI (capacitor-input) filter 
The mathematical equation to determine the value of inductor $(\mathrm{L})$, a capacitor $(\mathrm{C})$ and resistor $(\mathrm{R})$ are shown in equation (1) to (3):

$L<\frac{0.03 U_{\text {inV }}}{2 \pi I_{\text {Lmax }}}$

Where $\mathrm{U}_{\text {inv }}=\mathrm{V}_{\mathrm{DC} \text { supply }}=311 \mathrm{~V}, \mathrm{I}_{\mathrm{Lmax}}=10 \mathrm{~A}$

$C=\frac{1}{(2 \pi f c) L}$

$f_{s}=\frac{1}{2 \pi R C}$

\section{SIMULATION RESULTS}

In Figure 6 to Figure 8, the output voltage and current appear in the quasi-wave form for the inverter with quasi-wave switching technique. Harmonics of quasi-wave output voltage only consists of odd harmonic components due to odd and quarter-wave symmetrical characteristic. The disadvantages of quasi-wave switching technique, the quality of the output waveform is poor compared to unipolar and bipolar SPWM switching technique. Figure 6 shown the instantaneous line voltage for $\mathrm{V}_{\mathrm{ab}}, \mathrm{V}_{\mathrm{bc}}$, and $\mathrm{V}_{\mathrm{ca}}$, while for the phase voltage, $\mathrm{V}_{\mathrm{an}}, \mathrm{V}_{\mathrm{bn}}$, and $\mathrm{V}_{\mathrm{cn}}$, is shown in Figure 7 .

As presented in Figure 9 to Figure 11, the Total Harmonic Distortion (THD) percentage are measured from the output voltage and current for inverter circuit without filter. At this time, the quasi-wave produces highest THD compare to Sinusoidal Pulse Width Modulation (SPWM). The value of THD result for both output voltage is $31.45 \%$ (line voltage) and $31.26 \%$ (phase voltage). For the output current, the THD value is $31.26 \%$. These figures also show the amplitude of harmonic components are lower than the squarewave output waveform and there is no triple harmonic components occurs during this stage. Therefore, to increase the efficiency of the inverter, these THD values must be reduced by adding/designing the passive filters.
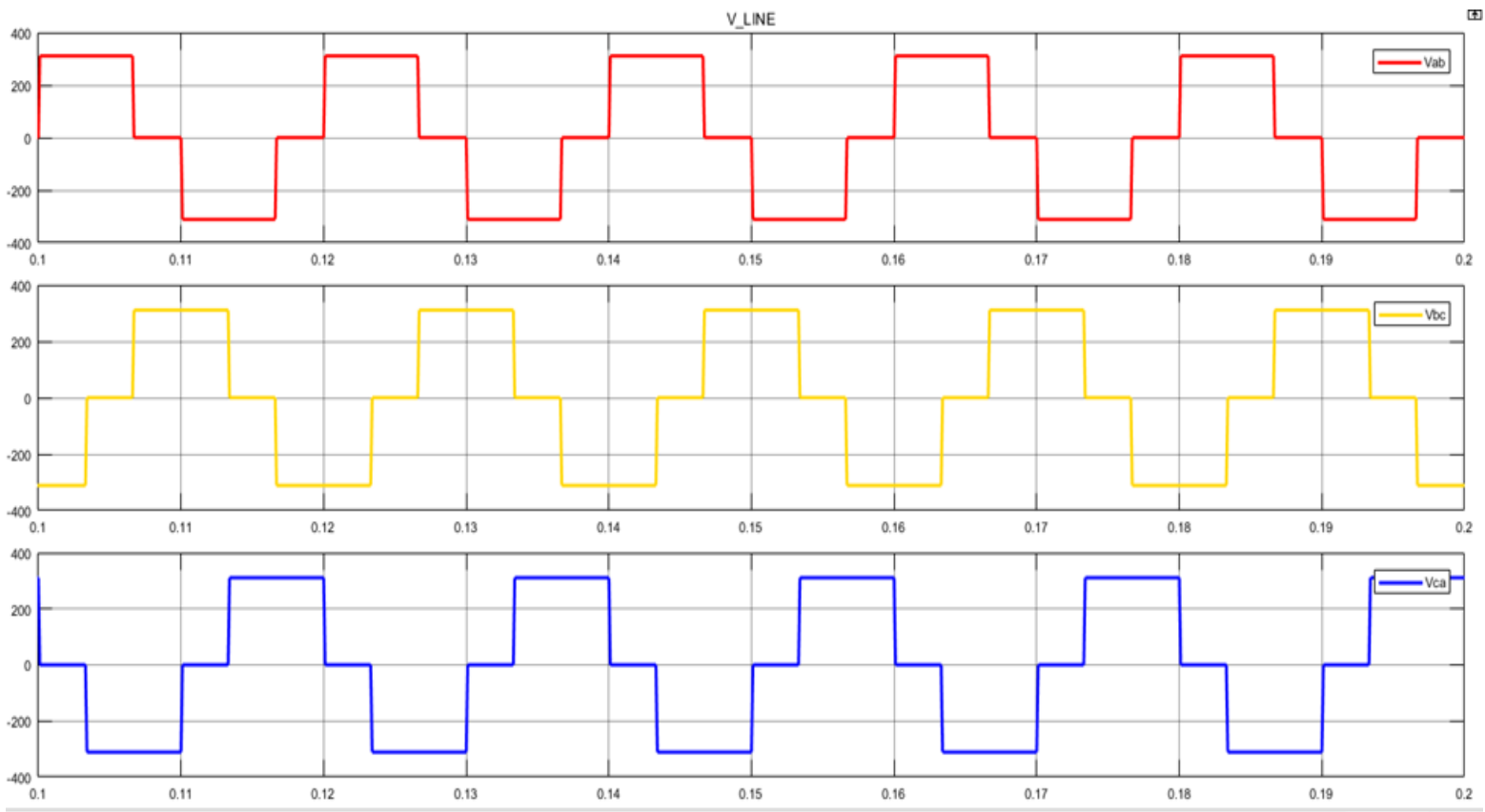

Figure 6. Line voltage (line-to-line) in $180^{\circ}$ conduction mode 

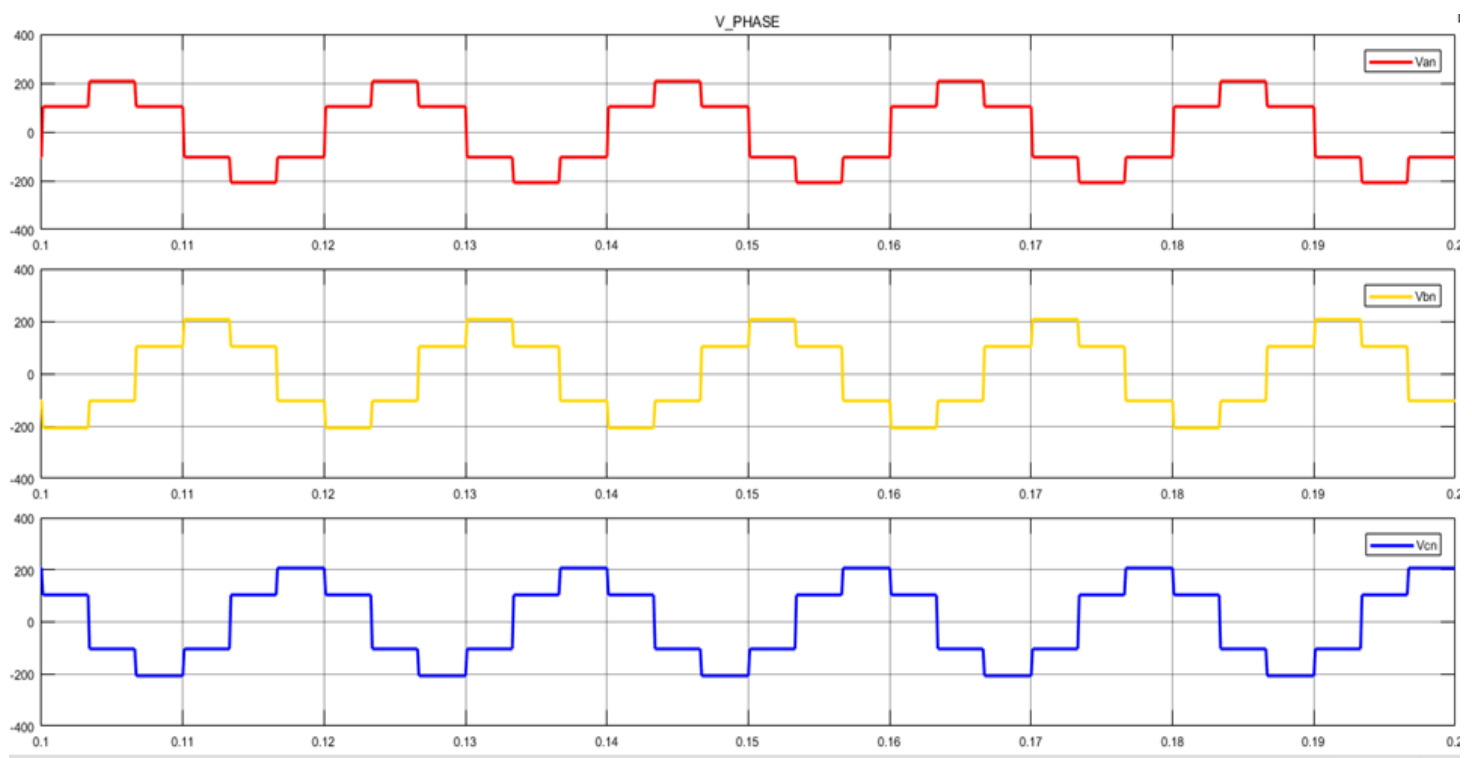

Figure 7. Phase voltage (line-to-neutral) in $180^{\circ}$ conduction mode
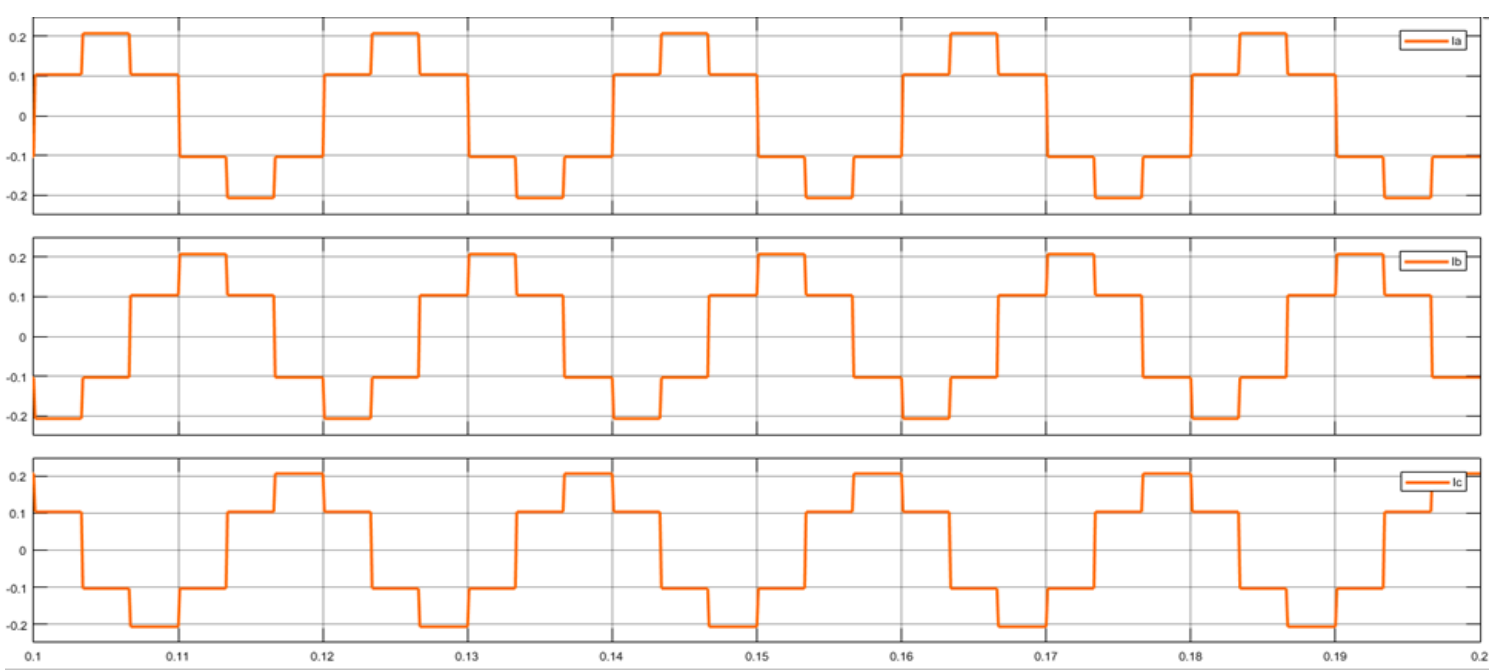

Figure 8. Output current in $180^{\circ}$ conduction mode

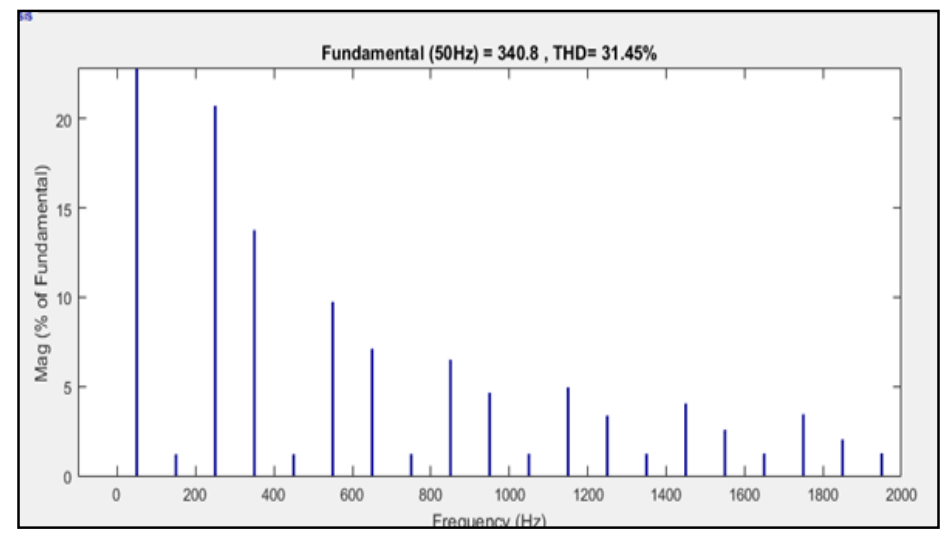


Figure 9. Total harmonic distortion (THD) at line voltage (line-to-line) for the quasi-wave without a passive filter

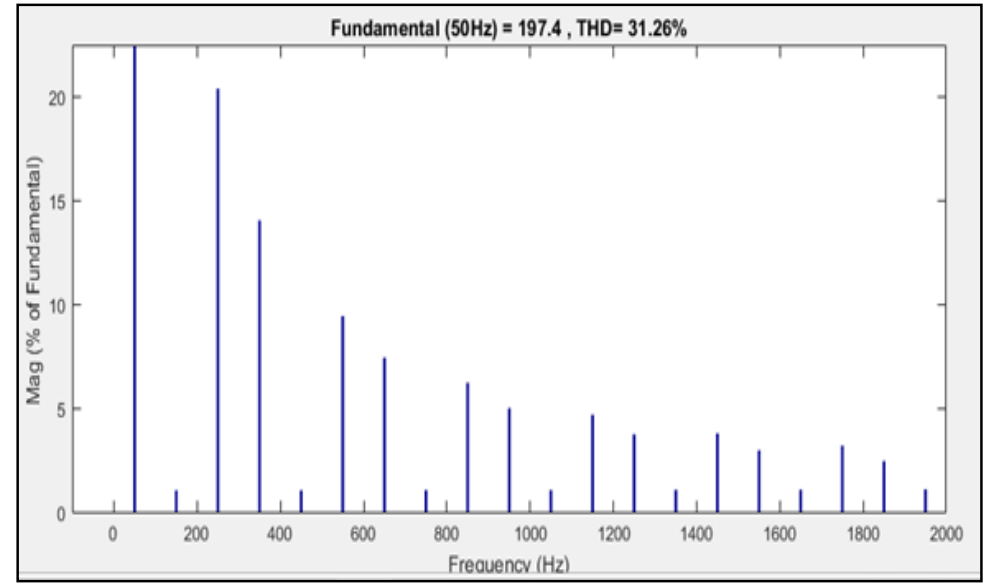

Figure 10. Total harmonic distortion (THD) at phase voltage (line-to-neutral) for the quasi-wave without a passive filter

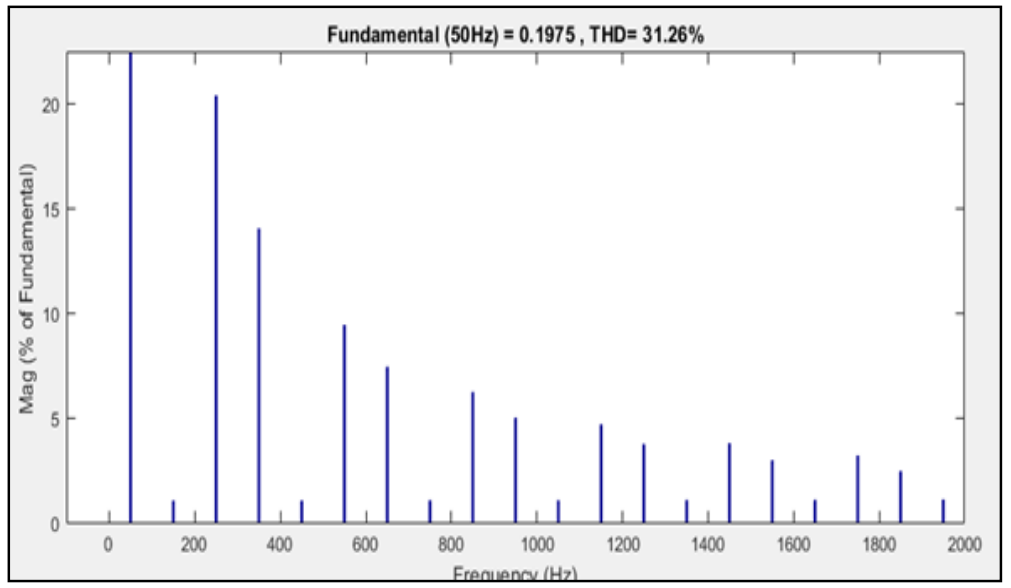

Figure 11. Total harmonic distortion (THD) at output current for the quasi-wave without a passive filter

Figure 12 shows the waveform and gating signals of three-phase inverter with bipolar SPWM technique in MATLAB/Simulink. The switching frequency $\left(\mathrm{f}_{\mathrm{s}}\right)$ used is $25 \mathrm{kHz}$. It can be observed from the figure, the upper three power switching device is a switch at the same time, which is different from the unipolar PWM where the devices are switched for a certain time only. For the Figure 13 and Figure 14, it show the output phase voltage, $\mathrm{V}_{\mathrm{an}}$ and line voltage, $\mathrm{V}_{\mathrm{ab}}$ without filter for bipolar SPWM technique.

With the same parameter, the THD percentage is measured from the inverter with bipolar SPWM technique and LC filter circuit by using Fast Fourier Transform (FFT). The function of LC filter is to supplies reactive power to the system while being highly effective in eliminating harmonic components. The inductor, $\mathrm{L}$, and a capacitor, $\mathrm{C}$ is a passive two-terminal electrical component that limits the charging or discharging current by stores electrical energy when the current flow through it. The THD value of the output voltage is $0.71 \%$ (line voltage) and $0.66 \%$ (phase voltage) which is similar to THD of output current.

Figure 15 to Figure 17 show the inverter output voltage and current with parameter shown in Table 3. All the figures show the sinusoidal waveform of the output inverter. These outputs are in the alternating waveform which is proved that three-phase inverter with LC filter is successfully operated by converting the DC input waveform into AC output waveform. The inverter output waveform is free from any harmonic distortion that can cause the voltage ripple on the waveform. For RC filter, Table 4 shown the parameter of the circuit. 

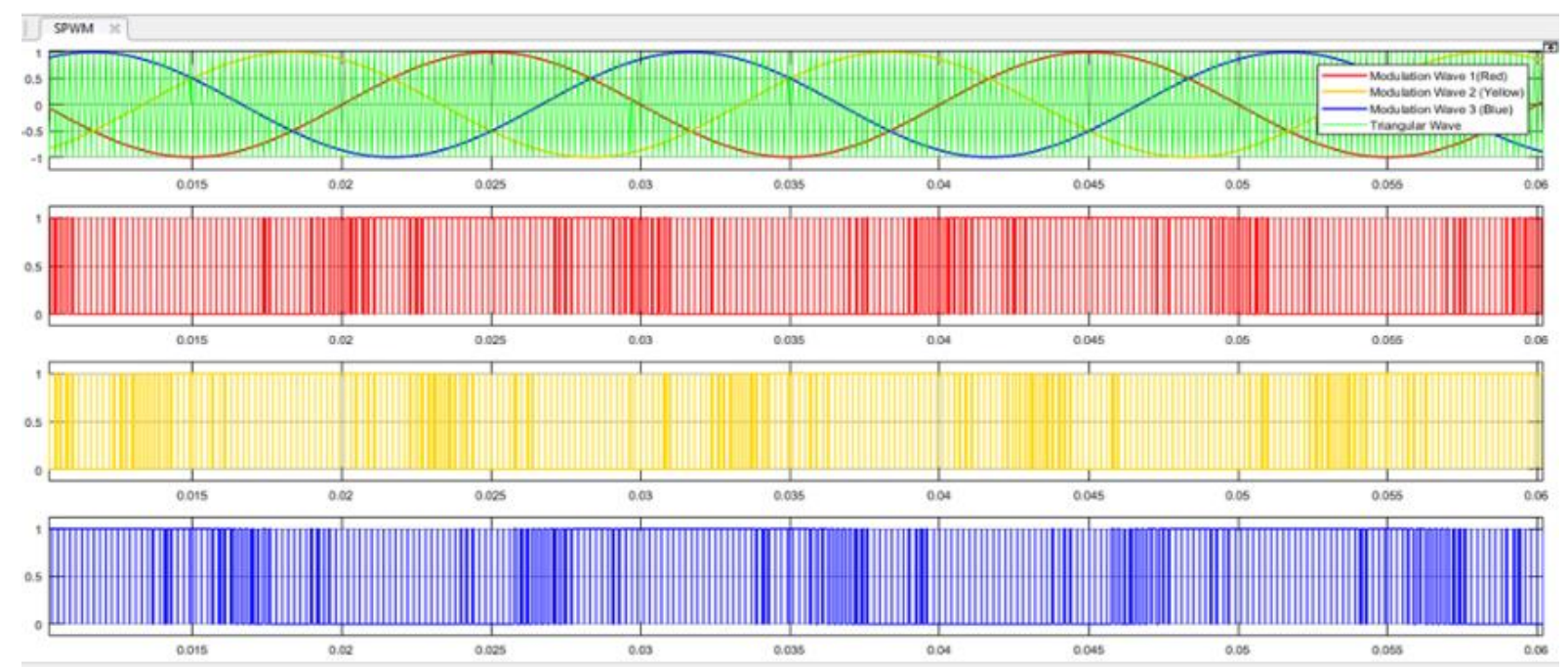

Figure 12. Bipolar SPWM modulation scheme on MATLAB/simulin

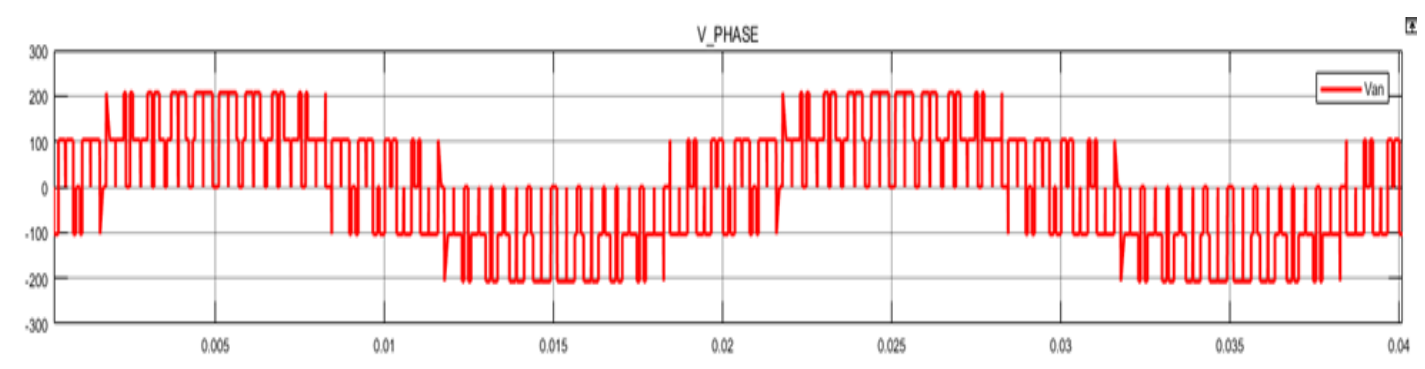

Figure 13. Bipolar SPWM phase voltage

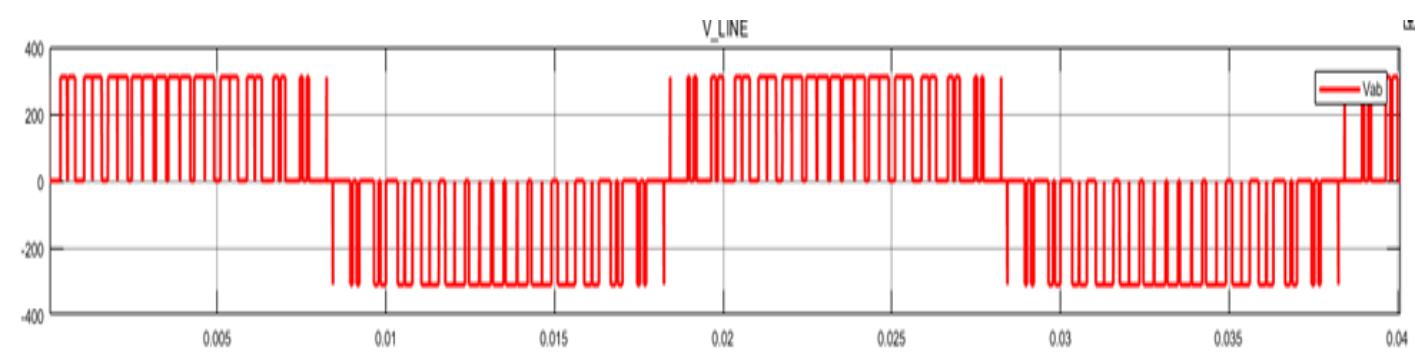

Figure 14. Bipolar SPWM line voltage

Table 3. Inverter Circuit Parameter with LC Filter

\begin{tabular}{ll}
\hline Parameters & Values \\
\hline DC Voltage source & $311 \mathrm{~V}$ \\
Switching frequency (fs) & $25 \mathrm{kHz}$ \\
Resistor (Load) & $1 \mathrm{k} \Omega$ \\
Inductor, L & $297 \mathrm{mH}$ \\
Capacitor, C & $13.65 \mu \mathrm{F}$ \\
\hline
\end{tabular}

Based on Figure 4, the inductor component is changed to the resistor component. The value of resistor was set as shown in Table 4. The THD value for line voltage, phase voltage, and the output current is same which is $1.84 \%$. Even though the THD value is higher than LC filter, but it can also be considered as an 
efficient filter due to THD is less than 5\% of the rated inverter output voltage and current. In Figure 19 to Figure 21, the output voltage and current inverter are smooth AC waveform which is proved that three-phase inverter with RC filter is also successfully operated by converting the DC input waveform into AC output waveform. The third filter is PI (capacitor-input) filter. Table 5 shown the parameter of PI (capacitor-input) passive filter.

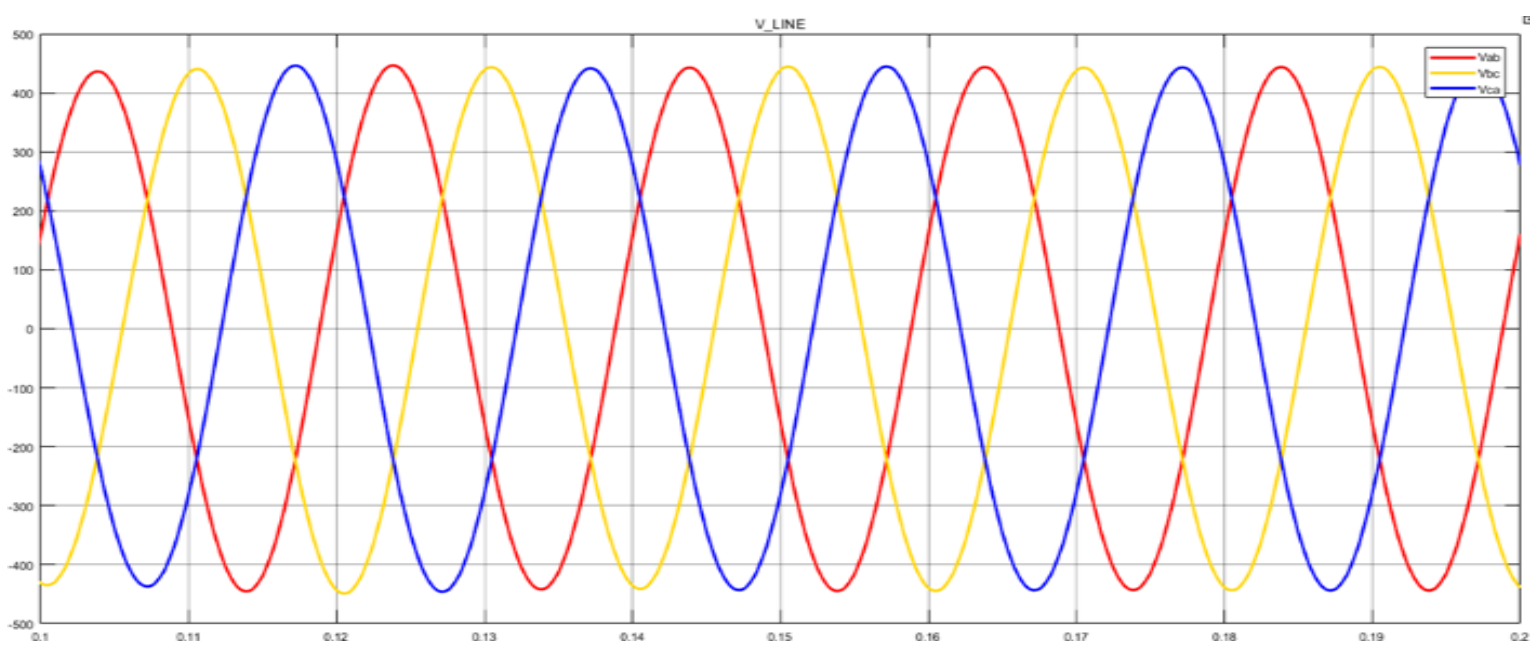

Figure 15. Line voltage (line-to-line) waveform of bipolar SPWM three-phase inverter with LC filter

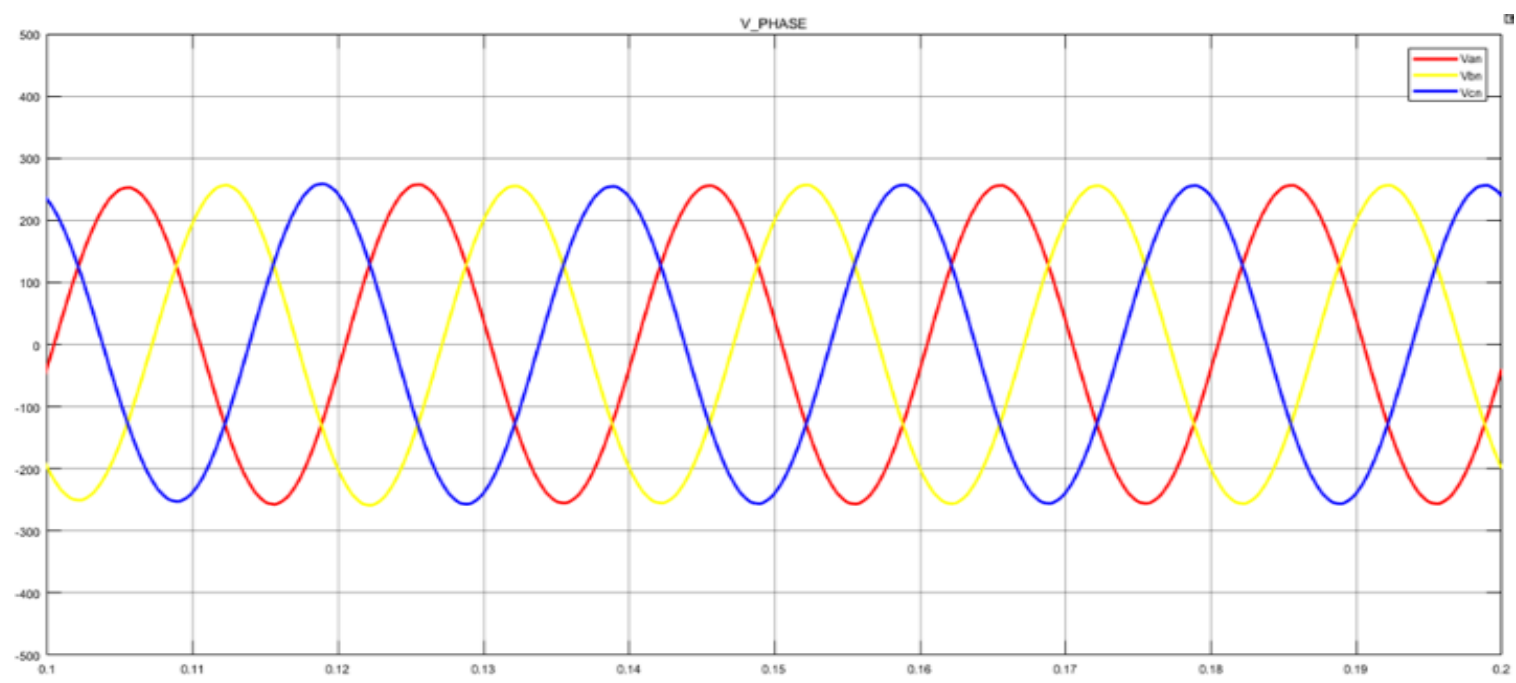

Figure 16. Phase voltage (line-to-neutral) waveform of bipolar SPWM three-phase inverter with LC filter 


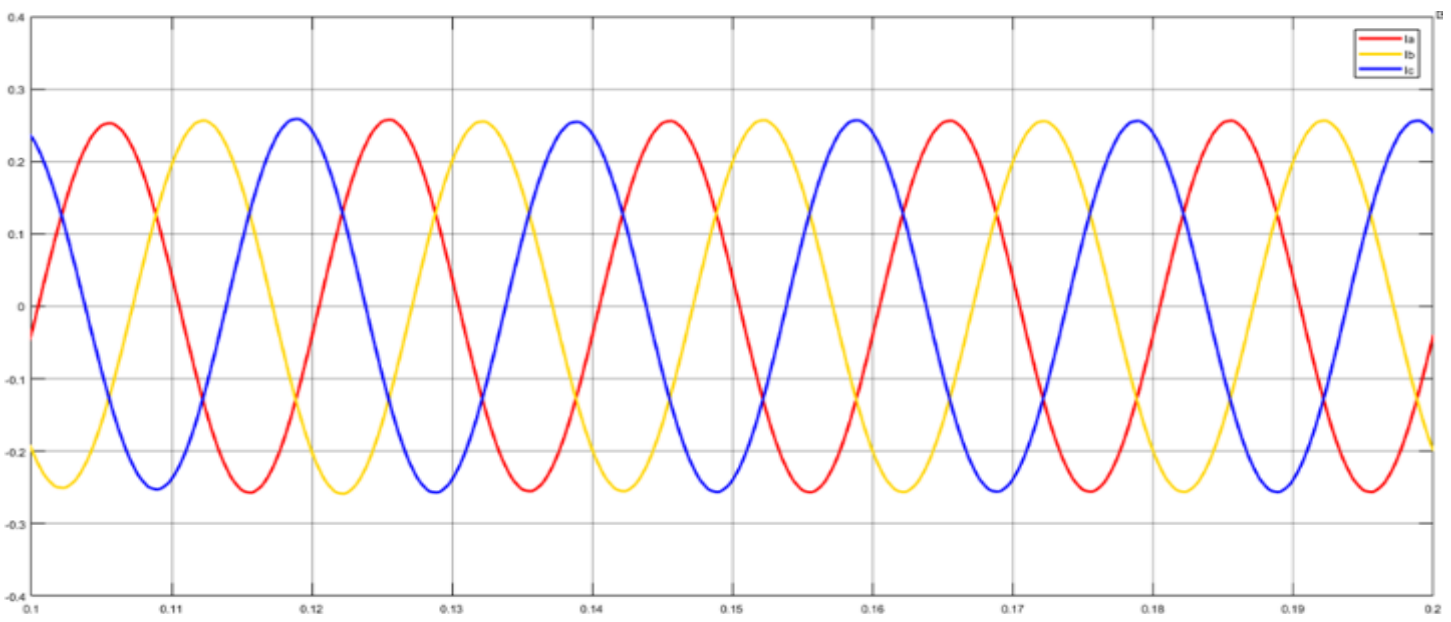

Figure 17. Output current waveform of bipolar SPWM three-phase inverter with LC filter

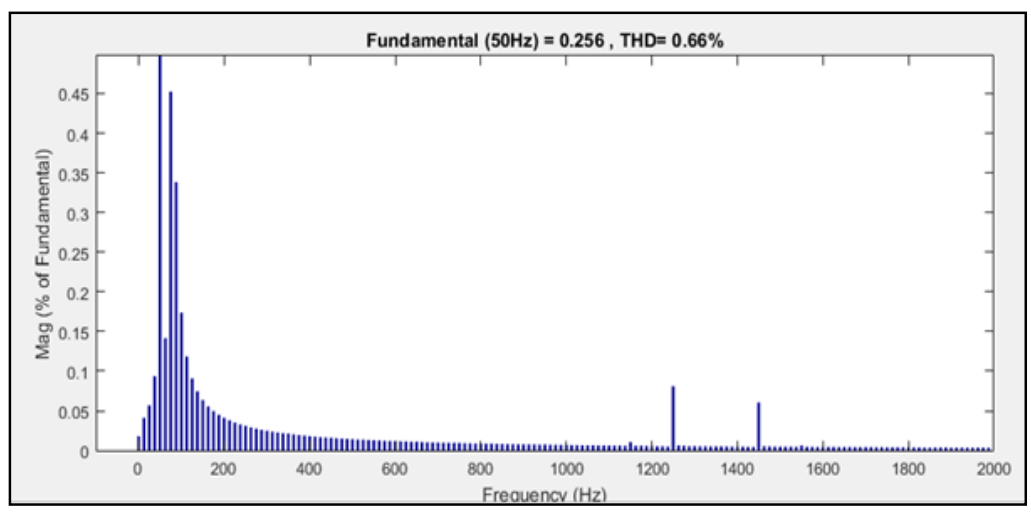

Figure 18. FFT analysis of output current inverter SPWM with $\mathrm{LC}$ filter when $\mathrm{L}=297 \mathrm{mH}$ and $\mathrm{C}=13.65 \mu \mathrm{F}$

Table 4. Inverter Circuit Parameter with RC Filter

\begin{tabular}{cc}
\hline Parameters & Values \\
\hline DC voltage source & $311 \mathrm{~V}$ \\
Switching frequency (fs) & $25 \mathrm{kHz}$ \\
Resistor (Load) & $1 \mathrm{k} \Omega$ \\
Resistor, $\mathrm{R}$ & $466.39 \mathrm{k} \Omega$ \\
Capacitor, C & $13.65 \mu \mathrm{F}$ \\
\hline
\end{tabular}

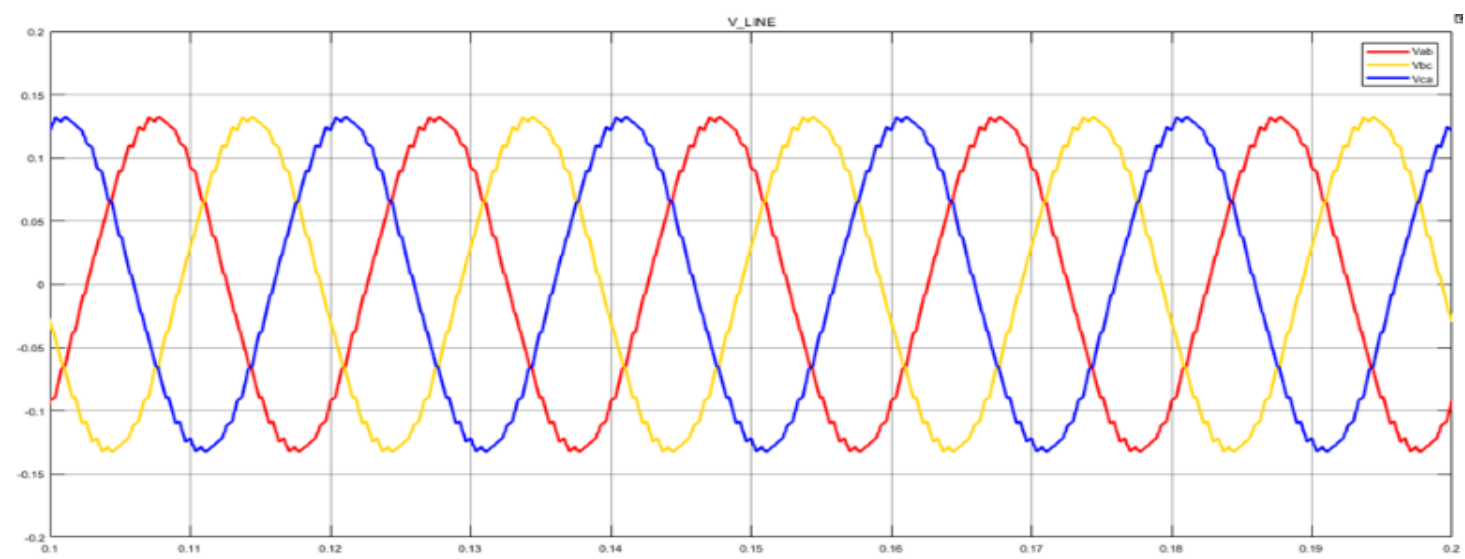

Figure 19. Line voltage (line-to-line) waveform of bipolar SPWM three-phase inverter with RC filter 


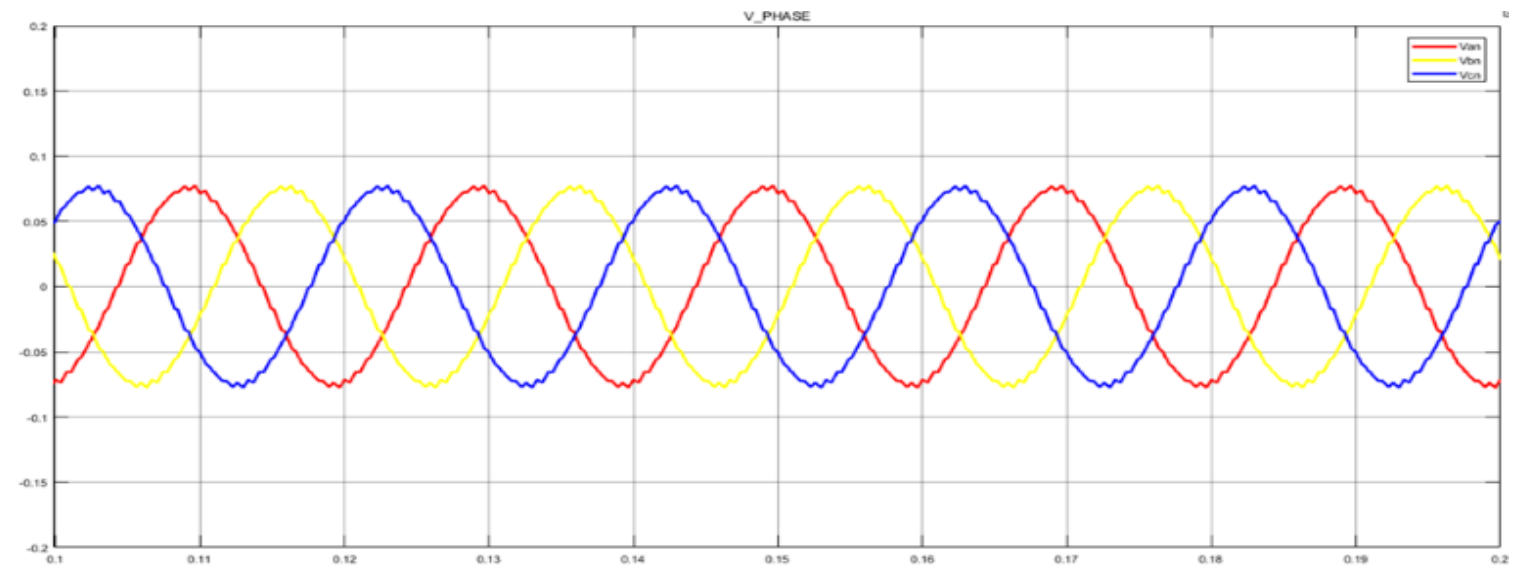

Figure 20. Phase voltage (line-to-neutral) waveform of bipolar SPWM three-phase inverter with RC filter

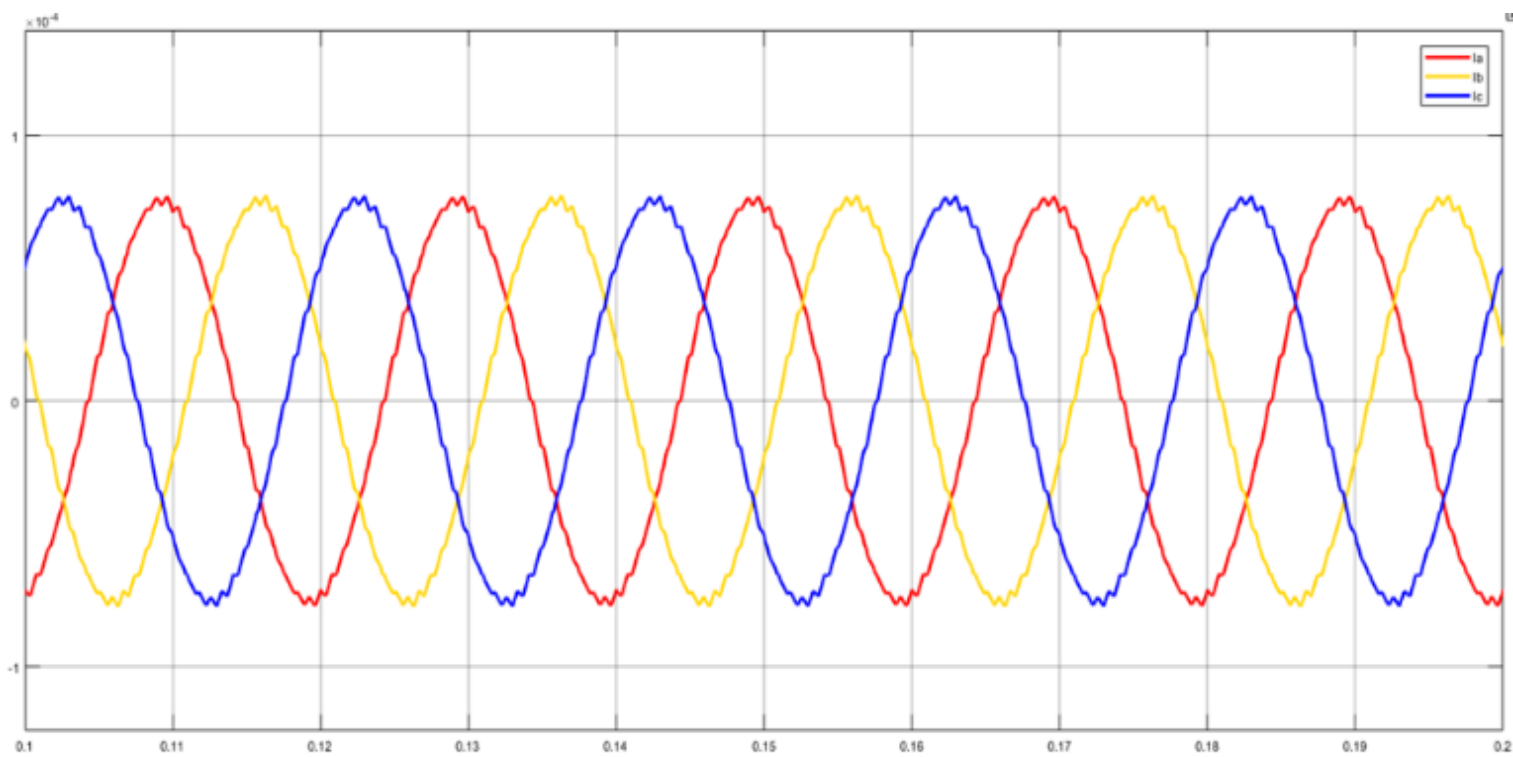

Figure 21. Output current waveform of bipolar SPWM three-phase inverter with RC filter

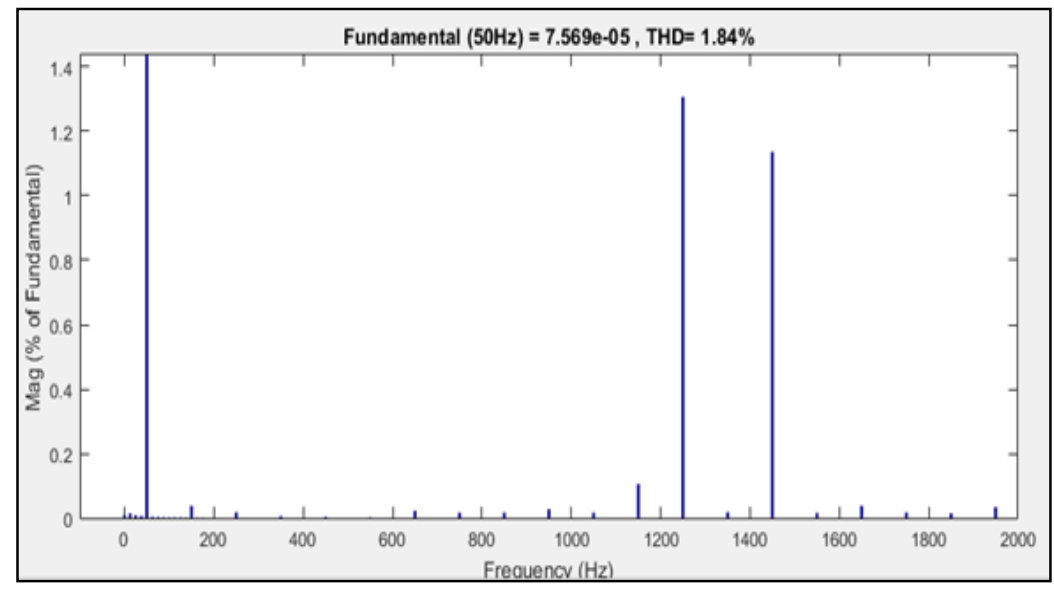

Figure 22. FFT analysis of output current inverter SPWM with $\mathrm{RC}$ filter when $\mathrm{R}=466.39 \mathrm{k} \Omega$ and $\mathrm{C}=13.65 \mu \mathrm{F}$

Table 5. Inverter Circuit Parameter with PI Filter 


\begin{tabular}{ll}
\hline Parameters & Values \\
\hline DC Voltage source & $311 \mathrm{~V}$ \\
Switching frequency (fs) & $25 \mathrm{kHz}$ \\
Resistor (Load) & $1 \mathrm{k} \Omega$ \\
Inductor, $\mathrm{L}$ & $297 \mathrm{mH}$ \\
Capacitor, $\mathrm{C}_{1}$ & $13.65 \mu \mathrm{F}$ \\
Capacitor, $\mathrm{C}_{2}$ & $13.65 \mu \mathrm{F}$ \\
\hline
\end{tabular}

Based on Figure 5, the circuit of PI (capacitor-input) filter may have two quantity number of capacitor component which is labeled as $\mathrm{C}_{1}$ and $\mathrm{C}_{2}$. For this type of passive filter, the THD value is $0.73 \%$ for line voltage and $0.67 \%$ for phase voltage and for output current. From these figure, the DC component value of line voltage for LC filter is 0.2190 and for PI (capacitor-input) filter is 0.2066 . Based on the observation, it can be concluded that PI (capacitor-input) filter is very efficient filter because the value of DC component is lower than LC filter and it is close to zero value. This can be concluded that PI filter is the best and efficient filter performance compared to LC and RC filter.

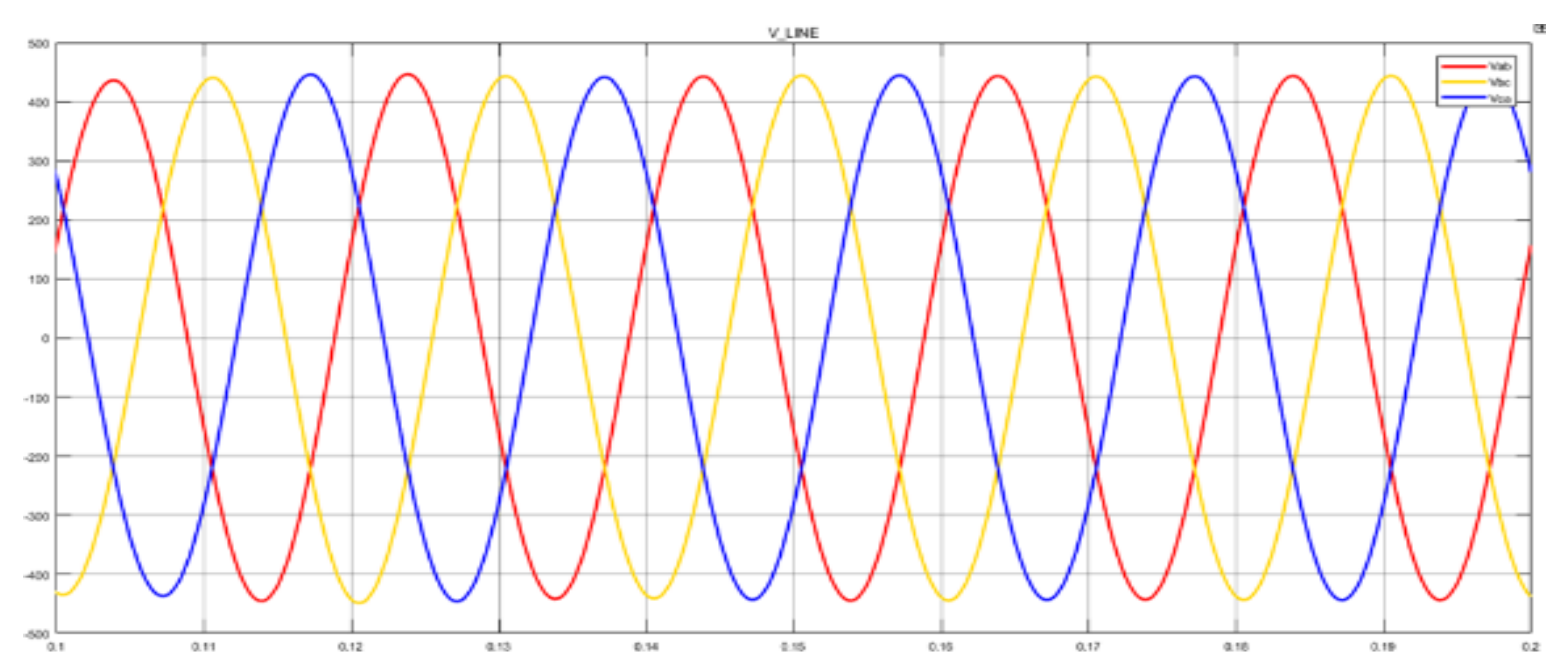

Figure 23. Line voltage (line-to-line) waveform of bipolar SPWM three-phase inverter with PI (capacitorinput) filter

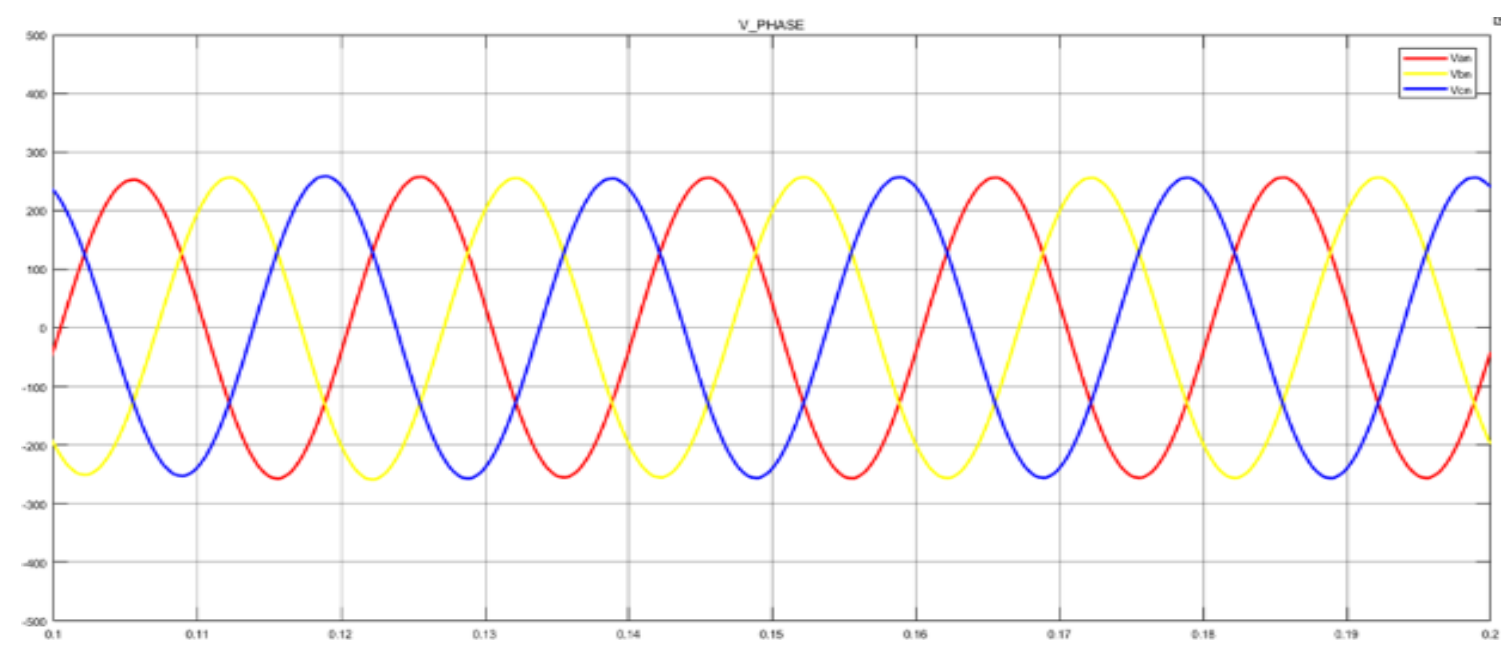

Figure 24. Phase VOLTAGe (line-to-neutral) waveform of bipolar SPWM three-phase inverter with PI (capacitor-input) filter 


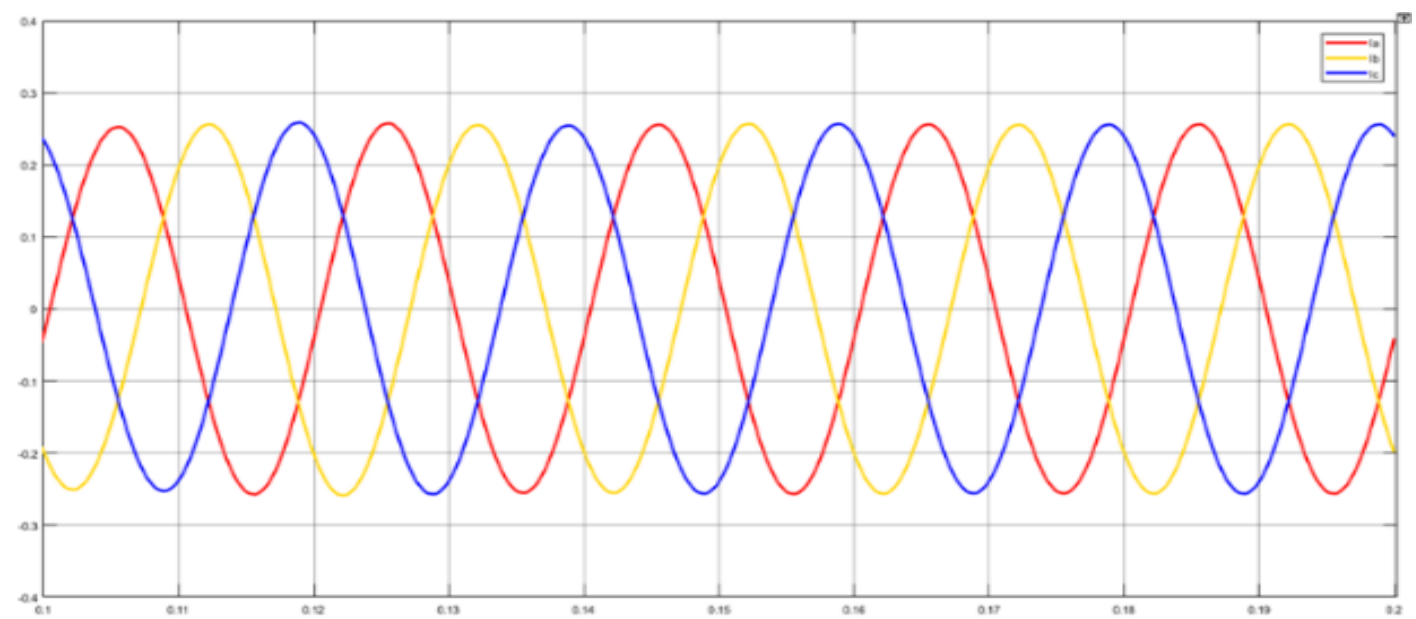

Figure 25. Output current waveform of bipolar SPWM three-phase inverter with PI (capacitor-input) filter

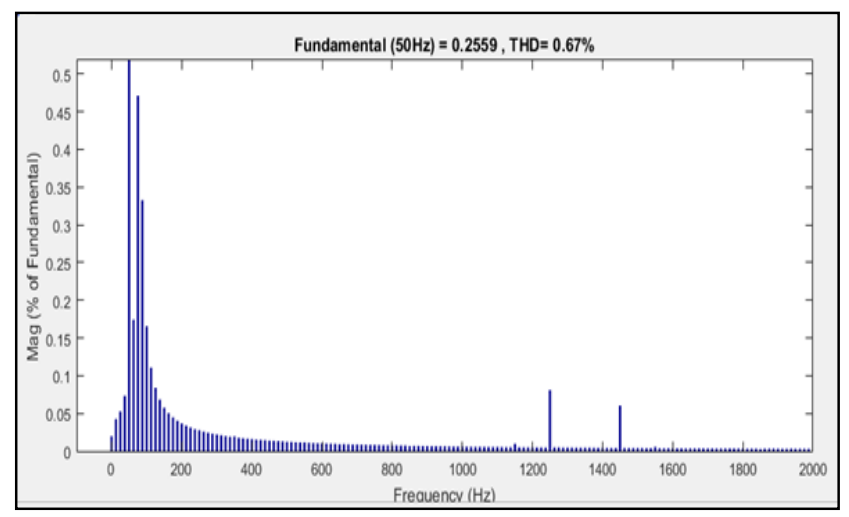

Figure 26. FFT analysis of output current inverter SPWM with PI (capacitor-input) filter when $\mathrm{L}=297 \mathrm{mH}$ and $\mathrm{C}_{1}=\mathrm{C}_{2}=13.65 \mu \mathrm{F}$

From the observation, THD values for LC filter and PI (capacitor-input) filter are almost the same. Refer to Figure 27, the differences value of THD at a line voltage between these two type of passive filter is $0.02 \%$, while for the phase voltage, it just only $0.01 \%$. Meanwhile, the differences value of THD at the output current is just only $0.01 \%$ as shown in Figure 29. From Figure 29 and Figure 30, the DC component value from FFT analysis is analyzed between LC and PI filter to determine the most efficient filter performance.

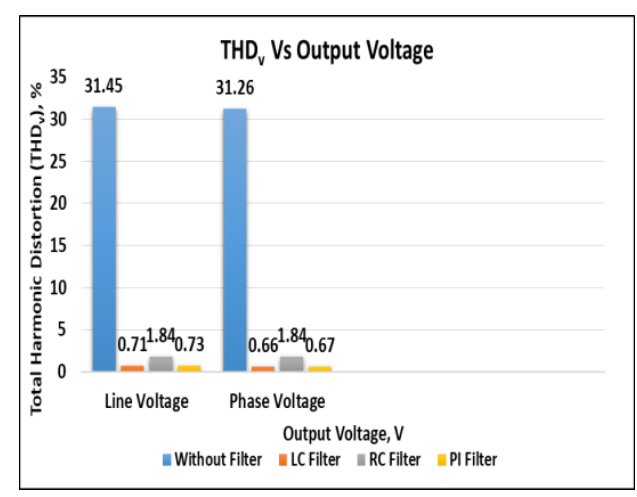

Figure 27. Bar chart of $\mathrm{THD}_{\mathrm{v}}$ Vs output voltage

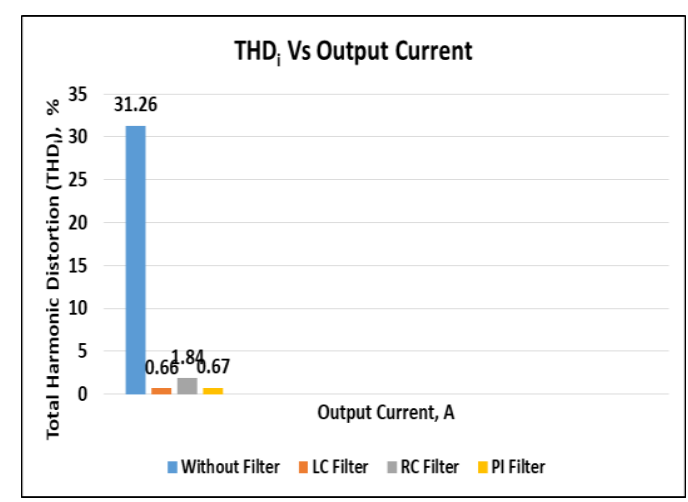

Figure 28. Bar chart of $\mathrm{THD}_{\mathrm{i}}$ Vs output current 


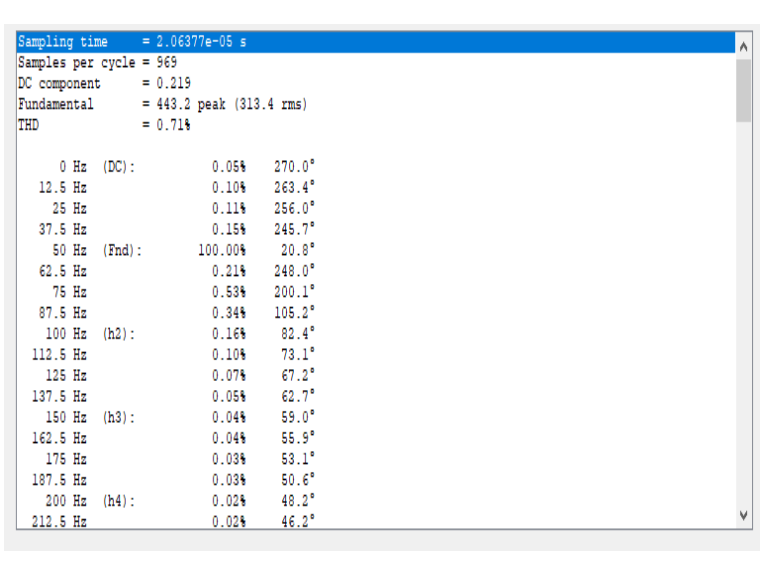

Figure 29. FFT analysis for DC component value for line voltage at LC filter

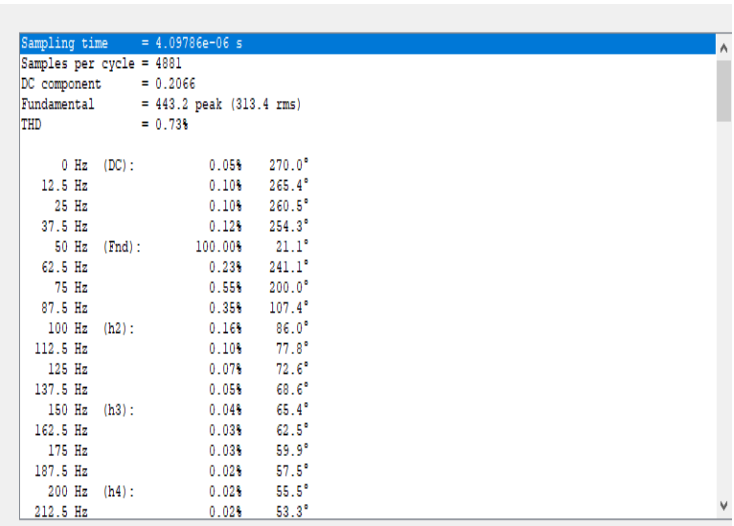

Figure 30. FFT analysis for DC component value for line voltage at PI (capacitor-input) filter

\section{CONCLUSION}

Investigation on filter performance at three-phase-inverter with $180^{\circ}$ conduction mode with quasi and bipolar SPWM technique is presented. From this investigation, it showed that all the passive filter designed which are LC, RC, and PI (capacitor-input) filter can be operated efficiently in a system with THD measurement less than $5 \%$ of the rated output. Finally, it can be concluded that the best filter among three types of passive filter is PI (capacitor-input) filter. PI filter consists of two quantity of capacitance which is $\mathrm{C}_{1}$ and $\mathrm{C}_{2}$ that provided the reactive power compensation to improve the power factor. The system can be improved with switching frequency higher than $25 \mathrm{kHz}$ and also can be tested with different type of load.

\section{ACKNOWLEDGEMENTS}

This research is supported by the Grant LESTARI 5/3/LESTARI (0160/2016) from Universiti Teknologi Mara (UiTM).

\section{REFERENCES}

[1] A. Gupta, "Three Phase Inverter Simulation using Sinusoidal PWM Technique", International Journal of Advanced Research in Electrical, Electronics and Instrumentation Engineering, vol. Vol.6, no. Issue 5, p. 4102, May 2017.

[2] M. S. J. Asghar, Power Electronics, New Delhi: Prentice-Hall of India Ltd, 2004.

[3] K. Dubey, Thyristorised Power Controllers, New Delhi: New Age International, 2001.

[4] D.A.Bradley, Power Electronics, Second Edi.Chapman \& Hall, 2-6 Boundry Row, London SE1 8HN, IK, 1987.

[5] S. Amol Anandrao Patil, "Harmonic mitigation using Passive Filter", International Journal of Engineering Trends and Technology (IJETT), Vols. Volume-45 Number 2, March 2017.

[6] [6] Sustainable Energy Development Authority (SEDA) Malaysia, "Procedure for The Testing And Commissioning Of Grid-Connected Photovoltaic Systems In Malaysia", SEDA, 2014.

[7] M. H. Rashid, Power Electronics Devices, Circuits, and Applications, Electrical and Computer Engineering University of West Florida: International Edition, 2014.

[8] P. Udakhe, D. Atkar, S. Chiriki, and V. B. Borghate, "Comparison of different types of SPWM techniques for three-phase seven level cascaded H-Bridge inverter" 1st IEEE Int. Conf. Power Electron. Intell. Control Energy Syst. ICPEICES 2016, pp. 1-5, 2017.

[9] A. M. Gole, "Sinusoidal Pulse width modulation", Power Electron., pp. 1-8, 2000.

[10] R. Kennel, "Power Electronics Exercise: Pulse Width Modulation Methods", vol. 49, no. 0, 2013.

[11] C. Townsend, T. J. Summers, and R. E. Betz, "Comparison of modulation strategies for a cascaded H-bridge StatCom- Part 2: Application of the analysis", IECON Proc. (Industrial Electron. Conf., pp. 2025-2031, 2010.

[12] M. I. Jahmeerbacus and M. Sunassee, "Evaluation of Selective Harmonic Elimination and sinusoidal PWM for single-phase DC to AC inverters under dead-time distortion”, IEEE Int. Symp. Ind. Electron., pp. 465-470, 2014.

[13] J. Niitsoo, M. Jankovic, P. Taklaja, J. Klüss, and I. Palu, "Power Quality Issues Concerning Photovoltaic Generation in Distribution Grids", Journal Smart Grid and Renewable Eneregy, June, pp. 148-163, 2015. 